\title{
KEEFEKTIFAN PENGGUNAAN MEDIA VLOG (VIDEO BLOGGING) DALAM KETERAMPILAN MENULIS TEKS NARASI SISWA KELAS VII SMP NEGERI 2 GAMPING TAHUN AJARAN 2018/2019
}

\author{
Nina Widyaningsih \\ Universitas PGRI Yogyakarta \\ ninawidyaningsih@gmail.com
}

\begin{abstract}
Abstrak: Penelitian ini bertujuan untuk mengetahui apakah media Vlog lebih efektif terhadap keterampilan menulis teks narasi siswa kelas VII SMP Negeri 2 Gamping. Penelitian ini dilakukan di SMP Negeri 2 Gamping. Jenis penelitian ini adalah eksperimen semu dengan desain The Nonequivalent Post-Test-Only Control Group Design. Kelas eksperimen menggunakan media vlog dan kelas kontrol menggunakan model pembelajaran langsung. Populasi penelitian ini adalah seluruh kelas VII SMP Negeri 2 Gamping. Sampel penelitian ini adalah siswa kelas VII C sebagai kelas eksperimen dan kelas VII E sebagai kelas Kontrol. Instrumen yang digunakan dalam penelitian ini adalah tes uraian yang telah diuji cobakan dan lembar observasi. Dari hasil uji coba instrumen tes uraian dinyatakan valid dan reliabel. Teknik analisis data yang digunakan adalah Uji t dengan taraf signifikan $\alpha=0,05$. Pengaruh penerapan media vlog telah diterapkan dengan baik, sesuai dengan prosedur yang benar, siswa juga menunjukan perubahan perilaku sesuai dengan indikator yang diharapkan. Setelah diterapkan media vlog siswa lebih mudah memahami pembelajaran menulis teks narasi dibandingkan dengan pembelajaran secara langsung tanpa menggunakan media vlog. Hal ini ditunjukan dengan hasil uji-t 6,661dengan db 58 dan $\mathrm{P}$ sebesar 0,000 . Hasil penelitian terbukti bahwa media vlog lebih efektif terhadap keterampilan menulis teks narasi siswa kelas VII SMP Negeri 2 Gamping. Hal ini ditunjukan dengan hasil nilai rata-rata di kelas eksperimen sebesar 80,73 dan nilai persentase di kelas kontrol sebesar 60,03 .
\end{abstract}

Kata Kunci: Keefektifan, Vlog, Menulis Teks Narasi

\section{EFFECTIVENESS OF MEDIA USAGE VLOG (VIDEO BLOGGING) INSIDE TEXT WRITING SKILLS NARRATIVE OF GRADE VII MIDDLE SCHOOL STUDENTS COUNTRY 2 GAMPING ACADEMIC YEAR 2018/2019}

Abstract: The aim of this study to find out whether the media Vlog is more effective against narrative text writing skills seventh grade students of State Middle School 2 Gamping. This research was conducted in Gamping 2 Public Middle School. Type this research is an experiment pseudo with the design Nonequivalent Post-Test-Only Control Group Design. Class experiment using media vlog and control class using a learning model directly. The population of this study are all VII grade middle school students Country 2 Gamping. Sample this research is class students VII C as an experimental class and class VII E as the Control class. Instruments used in this research is a description of the tested and sheet observe From the results of the trial description stated instruments they are valid valid. Analysis technique the data used is the t test with a significance level $=0.05$. Effect of media application vlog has been implemented well, according to the correct procedure, students also show change behavior according to the indicator which are expected. After applied more vlog media to students easy to understand learning narrative text writing compared with learning directly without using vlog media. This is shown with the t-test results of 6.661 with $\mathrm{db} 58$ and $P$ of 0,000 The results of the study are proven that vlog media is more effective towards text writing skills narrative of VII grade students of State Middle School 2 Gamping. This is shown with the results of the average value in the class experiment at 80.73 and value the percentage in the control class is equal to 60.03.

Keywords: Effectiveness, Vlogs, Writing Narrative Text 


\section{PENDAHULUAN}

Di dalam keterampilan berbahasa terdapat beberapa aspek, yaitu menyimak, membaca, berbicara, dan menulis. Dari beberapa aspek keterampilan berbahasa yang harus dikuasai terutama oleh siswa adalah keterampilan menulis. Menulis merupakan kegiatan kebahasaan yang memegang peran penting dalam proses pembelajaran pada siswa dan peradaban manusia. Dapat disimpulkan dengan menulis seseorang dapat berkomunikasi, mengemukakan ide-ide dan gagasan baik dari dalam maupun luar dirinya kemudian dituangkan dalam bentuk tulisan, dan mampu memperkaya pengalamannya.

Menulis mempunyai tujuan yaitu agar pembaca dapat mengetahui atau dapat menerima informasi yang disampaikan oleh si penulis tersebut. Selain mempunyai tujuan, menulis juga sering digunakan untuk melaporkan, memberitahu, dan mempengaruhi maksud yang hanya dapat dimengerti dengan baik oleh orang-orang yang dapat menyusun pikirannya dan mengutarakannya dengan jelas.

Keterampilan menulis merupakan suatu proses kreatif memindahkan gagasan ke dalam lambang-lambang tulisan. Menulis merupakan suatu bentuk berfikir, tetapi justru berfikir bagi membaca tertentu dan bagi waktu tertentu (Tarigan, 2008:23). Menurut Marwoto dalam Kusumaningsih dkk (2013:66) menulis merupakan kemampuan seseorang untuk mengungkap ide, pikiran dan pengalaman hidupnya dalam bahasa tulis yang runtut, eksprsif, enak dibaca, dan bisa dipahami orang lain.

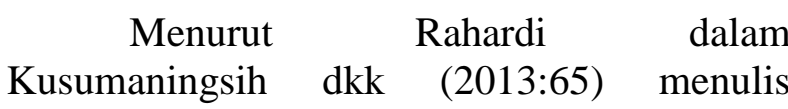
merupakan kegiatan menyampaikan sesuatu menggunakan bahasa melalui tulisan, dengan maksud dan pertimbangan tertentu untuk mencapai sesuatu yang dikehendakinya. Menurut Ajidarma dalam Yunus (2015:24) menulis adalah suatu cara untuk bicara, suatu cara untuk berkata, suatu cara untuk menyapa, suatu cara untuk menyentuh seseorang yang lain entah dimana. Menulis ialah menurunkan atau melukiskan lambang-lambang grafik yang menggambarkan suatu bahasa yang dipahami oleh seseorang, sehingga orang-orang lain dapat membaca lambang-lambang grafik tersebut kalau mereka memahami bahasa dan gambaran grafik lain (Tarigan, 2008:22).

Fungsi utama menulis menurut D'Angelo dalam Tarigan (2008:22) adalah sebagai alat komunikasi yang tidak langsung. Menulis sangat penting bagi pendidikan karena memudahkan para pelajar berfikir. Juga dapat menolong kita berfikir kritis. Menulis juga memudahkan kita merasakan dan menikmati hubungan-hubungan, memperdalam daya tanggapan atau resepsi kita, memecahkan masalah dan menyusun urutan sebagai pengalaman. Tulisan dapat membantu kita menjelaskan pikiran-pikran kita.

Tujuan utama menulis menurut Kusumaningsih dkk (2013:67) adalah sebagai alat komunikasi secara tidak langsung. Tujuan menulis menurut Tarigan (2008:24) yaitu: (1) memberitahukan atau mengajarkan, (2) meyakinkan atau mendesak, (3) menghibur atau menyenangkan, (4) mengutarakan atau mengekspresikan perasaan dan emosi yang berapi-api.

Keterampilan menulis tidak muncul begitu saja, tetapi membutuhkan waktu, proses latihan, dan mencoba terus menerus. Siswa tidak akan memperoleh keterampilan menulis hanya dengan duduk, mendengarkan penjelasan guru, dan mencatat penjelasan guru. Lemahnya keterampilan siswa dalam hal menulis disebabkan karena siswa enggan untuk menuliskan hal-hal kecil misalnya kehidupan sehari-hari mereka. Dalam menulis teks narasi yang menarik, siswa juga membutuhkan pengetahuan dan cara atau model yang menarik.

Kesulitan-kesulitan yang dialami para siswa dalam menulis teks narasi tersebut, siswa belum terbiasa membuat sebuah karangan teks narasi. Kesulitan tersebut disebabkan oleh kemampuan siswa yang masih kurang atau pemilihan model yang kurang tepat. Faktor lain yang menjadi hambatan keterampilan menulis teks narasi adalah faktor guru. Guru sering menggunakan media, pendekatan, teknik atau model yang kurang tepat. Peran guru sangat penting dalam proses pembelajaraan berlangsung dan dalam 
menumbuhkan motivasi siswa untuk menciptakan suasana belajar yang tidak membosankan.

Menurut Semi dalam Kusumaningsih dkk (2013:13) menyatakan narasi merupakan bentuk percakapan atau tulisan yang bertujuan menceritakan rangkaian peristiwa atau pengalaman manusia berdasarkan perkembangan dan waktu ke waktu. Teks narasi sebagai suatu cerita, yang bermaksud memberitahukan kepada pembaca atau pendengar apa yang diketahui dan dialaminya agar dapat merasakan peristiwa tersebut akan menimbulkan kesan di hatinya.

Sedangkan menurut Keraf (2010:36) narasi merupakan suatu bentuk wacana yang berusaha menggambarkan dengan sejelasjelasnya kepada pembaca suatu peristiwa yang telah terjadi.

Ada beberapa cara untuk mengatasi kesulitan-kesulitan siswa dalam menulis teks narasi adalah dengan memberikan pengetahuan dasar tentang teks narasi dan menulis teks narasi, memberikan bimbingan menulis serta pendekatan, media dan teknik atau model yang akan digunakan hendaknya mampu menumbuhkan minat siswa dalam menulis teks narasi. Alternatif untuk mengatasi kesulitan para siswa dalam pembelajaran menulis teutama menulis teks narasi dengan menggunakan sebuah media yang menarik dan menyenangkan salah satunya yaitu media vlog (video blogging).

Kata media berasal dari bahasa Latin dan merupakan bentuk jamak dari kata medium yang secara harfiah dapat diartikan sebagai perantara atau pengantar (Sanjaya, 2008:204). Kata media berasal dari bahasa Latin medius yang secara harfiah berarti 'tengah', 'perantara' atau 'pengantar'. Dalam bahasa Arab, media adalah perantara ( و سائل ) atau pengantar pesan dari pengirim kepada penerima pesan (Arsyad, 2017:3).

\section{Association for Educational}

Communications and Technology (AECT, 1997) mendefinisikan media sebagai segala bentuk yang digunakan untuk menyalurkan informasi. Berbeda dengan pendapat Briggs yang mengatakan bahwa media pada hakikatnya adalah peralatan fisik untuk membawakan atau menyempurnakan isi pembelajaran (Anitah, 2009:4).

Gerlach dan Ely menjelaskan pula bahwa media adalah grafik, fotografi, elektronik, atau alat-alat mekanik untuk menyajikan, memproses, dan menjelakan informasi lisan atau visual. Media adalah setiap orang, bahan, alat, atau peristiwa yang dapat menciptakan kondisi yang memungkinkan pembelajaran untuk menerima pengetahuan, keterampilan, dan sikap. Dengan pengertian itu maka guru, buku ajar, serta lingkungan adalah media (Anitah, 2010:5).

Azhar Arsyad (2017:49) menyatakan bahwa video merupakan gambar-gambar dalam frame, di mana frame demi frame diproyeksikan melalui lensa proyektor secara mekanis sehingga pada layar terlihat gambar hidup. Menurut Kustandi dan Sudjipto (2011) video merupakan film bergerak dengan cepat dan bergantian, sehingga memberikan visualisasi yang kontinyu. Video dapat menggambarkan suatu objek yang bergerak bersama-sama dengan suara alamiah atau suara yang sesuai.

Video blogging atau biasa disebut vlog. Video ini juga sering disebut dengan nama video catatan harian si pembuat. Vlog berisi rekaman kegiatan sehari-hari dari seseorang yang mungkin penting, misalnya seorang presiden, atau bahkan masyarakat biasa yang dianggap gaya hidupnya menarik. Video jenis ini sangat mudah dibuat, tidak membutuhkan peralatan yang canggih, ataupun naskah. Dalam pembuatan video ini hanya memerlukan kamera video yang ringan dan mudah dibawa untuk merekam (Jubilee, 2018).

Media pembelajaran berbasis video vlog ini merupakan media audio-visual yang termasuk dalam interactive video multimedia, dimana disajikan berupa gambar bergerak, berisi pesan atau informasi pembelajaran meliputi rangsangan yang variatif (audiovisual). Media video berbasis vlog ini memungkinkan terjadinya interaksi komunikasi lebih dari satu arah antara komponen-komponen komunikasi, dalam hal ini guru, media, dan siswa. 
Seiring dengan perkembangan zaman, ilmu pengetahuan dan teknologi juga mengikutinya. Dari perkembangan tersebut, dapat dimanfaatkan dengan baik pada dunia pendidikan. Salah satu cara memanfaatkan perkembangan di atas, yaitu dengan cara pengembangan. Pengembangan hasil dari perkembangan teknologi dan memanfaatkan sarana prasarana yang ada disekitarnya, diantaranya adalah video yang dapat dimanfaatkan sebagai media pembelajaran dengan memutarkan saat pembelajaran berlangsung menggunakan LCD proyektor.

Video yang sudah dikembangkan sesuai dengan aspek-aspek pembelajaran dapat diterapkan untuk menyampaikan materi pembelajaran. Arzyad (2013:173) menyatakan bahwa "video merupakan media pembelajaran yang efektif untuk membantu proses belajar mengajar. Dengan video siswa dapat mengakses secara langsung informasi yang terkandung dalam video dengan mudah. Multimedia berbasis komputer ini sangat menjanjikan penggunaannya dalam bidang pendidikan."

\section{METODE PENELITIAN}

Metode penelitian ini akan membahas tujuh hal pokok, yaitu (1) pendekatan penelitian, (2) subjek penelitian, (3) tempat dan waktu penelitian, (4) instrumen penelitian, (5) pengumpulan data, dan (6) analisis data. Berikut ini pemaparan masing-masing subbab tersebut.

Pendekatan yang digunakan dalam penelitian ini adalah pendekatan survai.
Pendekatan survai adalah prosedur penelitian yang menggunakan kajian eksploratoris untuk mengetahui keterampilan menulis siswa kelas VII SMP Negeri 2 Gamping . Data-data penelitian diperoleh dari tes yang dikerjakan oleh siswa. Data-data yang diperoleh kemudian dianalisis dan dilihat perubahannya

Subjek penelitian ini adalah siswa kelas VII SMP Negeri 2 Gamping. Penelitian ini dilakukan pada siswa kelas VII SMP Negeri 2 Gamping pada mata pelajaran Bahasa Indonesia.

Penelitian ini dilaksanakan di SMP Negeri 2 Gamping. Populasi penelitian ini adalah siswa kelas VII SMP Negeri 2 Gamping. Untuk waktu penelitian ini dilakukan pada bulan Agustus sampai dengan November 2018 pada jam dan hari kerja. Penelitian ini akan dilaksanakan sesuai dengan kesepakatan guru bahasa Indonesia.

Instrumen dalam penelitian ini menggunakan pre test dan post test. Lembar pre test dan post test sebelum digunakan didiskusikan dan divaliditas oleh ahli sekaligus pembimbing. Tes digunakan atau diberikan pada siswa untuk mengetahui keefektivan vlog (video blogging) sebagai media untuk menulis teks narasi.

Pengumpulan data menggunakan pre test dan post test. Data yang terkumpul melalui, kemudian dianalisis secara deskriptif. Analisis data melalui kategorisasi atau pengelompokan setiap komponen. Data-data dikelompokan dan dideskripsikan untuk menjawab rumusan dalam penelitian ini.

\section{HASIL PENELITIAN DAN PEMBAHASAN \\ Gambaran nilai mengenai hasil pembelajaran menulis teks narasi siswa dapat dilihat pada tabel berikut.}

Nilai Rata-Rata, Uji Normalitas, Uji Homogenitas, Uji Hipotesis

\begin{tabular}{|l|l|l|l|l|}
\hline No & \multirow{2}{*}{ Para meter } & Perlakuan & keterangan \\
\cline { 3 - 4 } & & eksperimen & kontrol & \\
\hline 1 & Rata-rata & 80,73 & 60,03 & Eksperimen $>$ kontrol \\
\hline 2 & Uji Normalitas & $\begin{array}{l}\mathrm{t}_{\mathrm{h}}: 0,200 \\
\mathrm{t}_{\mathrm{t}}: 0,151\end{array}$ & $\begin{array}{l}\mathrm{t}_{\mathrm{h}}: 0,133 \\
\mathrm{t}_{\mathrm{t}}: 0,250\end{array}$ & $\begin{array}{l}\mathrm{t}_{\mathrm{h}}>\mathrm{t}_{\mathrm{t}} \text { (Normal) } \\
\mathrm{t}_{\mathrm{h}}>\mathrm{t}_{\mathrm{t}} \text { (Normal) }\end{array}$ \\
\hline 3 & Uji homogenitas & $\mathrm{t}_{\mathrm{h}}: 1,382$ & $\mathrm{t}_{\mathrm{h}}>\mathrm{t}_{\mathrm{t}}$ (Homogen) \\
& & $\mathrm{t}_{\mathrm{t}}: 0,245$ & \\
\hline 4 & Uji hipotesis & $\mathrm{t}_{\mathrm{h}}: 21,200$ & $\mathrm{t}_{\mathrm{h}}>\mathrm{t}_{\mathrm{t}}$ Maka $\mathrm{H}_{\mathrm{a}}$ DITERIMA \\
& & $\mathrm{t}_{\mathrm{t}}: 6,878$ & \\
\hline
\end{tabular}

Setelah dilakukan beberapa pengujian dapat disimpulkan bahwa terdapat efektifitas yang signifikan antara pembelajaran menulis teks narasi dengan media dengan pembelajaran menulis teks narasi menggunakan media konvensional. Hasil belajar siswa dalam menulis teks narasi dengan media Vlog lebih efektif.

1. Deskripsi Kondisi Awal Pembelajaran Menulis Teks Narasi Kelompok Kontrol dan Kelompok Eksperimen Siswa Kelas VII SMP Negeri 2 Gamping. 
Kondisi awal pada kelompok eksperimen dan kelompok kontrol dalam penelitian ini diketahui dengan melakukan pretest. Pretest yang dilakukan untuk menjaring data pembelajaran menulis teks narasi siswa kelas VII SMP Negeri 2 Gamping. Penjaringan data dilakukan dengan instrumen penelitian berupa tes pembelajaran menulis teks narasi yang berbentuk tes esay sebanyak 1 butir soal.

Dari hasil pretest tersebut diperoleh skor kemampuan awal pembelajaran menulis teks narasi pada kelompok kontrol dan kelompok eksperimen. Adapun skor pretest yang diperoleh pada kelompok kontrol skor tertinggi sebesar 73, skor terendah sebesar 33, mean sebesar 58,63, dan standar daviansi sebesar 10,84. Sementara skor pretest yang diperoleh kelompok eksperimen skor tertinggi sebesar 80, skor terendah sebesar 33, mean sebesar 59,53, dan standar daviansi sebesar 11,88. Data skor pretest kelompok kontrol dan kelompok eksperimen selanjutnya dianalisis dengan menggunakan uji-t untuk mengetahui ada tidaknya perbedaan yang signifikan antara kemampuan awal pembelajaran menulis teks narasi pada kedua kelompok tersebut.

Hasil analisis uji-t diperoleh $t_{\text {hitung }}$ adalah sebesar 0,181 dengan df sebesar 58. Kemudian skor $t_{\text {hitung }}$ tersebut dikonsultasikan dengan nilai $\mathrm{t}_{\text {tabel }}$ pada taraf signifikan 0,05 dan df 58. Skor $t_{\text {tabel }}$ pada taraf signifikansi $5 \%$ dan df 58 adalah sebesar 0,306. Hal ini menunjukkan bahwa skor $\mathrm{t}_{\text {hitung }}$ lebih kecil dari $\mathrm{t}_{\text {tabel }}(0,181<0,306)$ dan sig (P) lebih besar dari 0,05 (.0,760<0,05) maka dinyatakan pretest kelompok eksperimen dan kelompok kontrol tidak signifikan karena tidak memenuhi syarat taraf signifikan dimana $t_{\text {hitung }}$ kurang dari $t_{\text {tabel }}$ sedangkan $\mathrm{P}$ kurang dari taraf signifikan 5\%. Maka dapat disimpulkan bahwa skor pretest pembelajaran menulis teks narasi yang dimiliki kedua kelompok tidak ada perbedaan, hal ini menunjukkan bahwa kedua kelompok berangkat dari titik tolak yang sama sebelum diberi perlakuan.

\section{Perbedaan Pembelajaran Menyimak Puisi} Siswa Kelas VII SMP Negeri 2 Gamping. Antara Kelompok Yang Menggunakan Media Vlog dan Kelompok yang Menggunakan Media Konvensional.

Hasil pretest pembelajaran menulis teks narasi kelompok kontrol dan kelompok eksperimen menunjukkan bahwa tidak ada perbedaan tingkat pembelajaran menulis teks narasi antara kedua kelompok tersebut. Hal ini menunjukkan bahwa kelompok kontrol dan kelompok eksperimen berangkat dari titik tolak yang sama. Setelah kedua kelompok dianggap sama, masing-masing kelompok diberi perlakuan. Siswa kelompok kontrol pembelajaran menulis teks narasi menggunakan media konvensional, sedangkan siswa kelompok eksperimen pembelajaran menulis teks narasi menggunakan media Vlog.

Setelah mendapat pembelajaran menulis teks narasi dengan menggunakan media vlog skor posttest pembelajaran menulis teks narasi kelompok eksperimen mengalami peningkatan yang cukup tinggi, sedangkan kelompok kontrol yang menggunakan media konvensional hanya mengalami sedikit peningkatan. Diketahui dari skor rata-rata pretest kelompok eksperimen sebesar 59,53 dan skor rata-rata posttest sebesar 80,73 yang berarti terjadi peningkatan pembelajaran menulis teks narasi sebesar 21,2. Pada kelompok kontrol diketahui skor rata-rata pretest sebesar 58,63 dan skor rata-rata posttest sebesar 60,03 yang terjadi peningkatan pembelajaran menulis teks narasi sebesar I,4. Hal ini menunjukkan bahwa peningkatan rata-rata pembelajaran menulis teks narasi kelompok eksperimen lebih tinggi dari pada kelompok kontrol.

\section{Tingkat Keefektifan Penggunaan Media Vlog Dalam Pembelajaran Menulis Teks Narasi Siswa Kelas VII SMP Negeri 2 Gamping.}

Selain mendeskripsikan perbedaan pembelajaran menulis teks berita kelompok kontrol dan kelompok eksperimen, penelitian ini juga bertujuan mendeskripsikan keefektifan media vlog dalam pembelajaran menulis teks berita siswa kelas VII SMP Negeri 2 Gamping. Keefektivan penggunaan media vlog dalam pembelajaran menulis teks berita kelas VII SMP Negeri 2 Gamping dilihat dari perbedaan uji-t pretest dan posttest kelompok kontrol dan kelompok eksperimen.

Berdasarkan hasil analisis $u j i-t$ data pretest dan posttest kelompok kontrol diperoleh nilai $t_{\text {hitung }}$ sebesar 1.400, t tabel sebesar $1.380(1.400>1.380)$, dan $\mathrm{P}$ sebesar 0,178 pada taraf signifikan 0,05 (P $>0,05)$ dengan df 29. Dapat disimpulkan bahwa pretest dan posttest kelompok kontrol tidak signifikan karena dari hasil tabel di dapat $t_{h}>t_{t}$ dan P>0,05 tidak sesuai dengan Syarat dan bersifat signifikansi apabila $t_{\text {hitung }}$ lebih besar dari $\mathrm{t}_{\text {tabel }}$ dan $\mathrm{P}$ lebih kecil dari 0,05 (5\%).

Hal ini berbeda dengan hasil analisis $u j i-t$ data pretest dan posttest kelompok eksperimen pembelajaran menyimak puisi kelompok 
eksperimen diperoleh $t_{\text {hitung }}$ sebesar 21.200, $t_{\text {tabel }}$ sebesar $6.878 \quad(21.200>6.878)$, dan $\mathrm{P}$ sebesar 0,000 pada taraf signifikan $0,05(\mathrm{P}>0,05)$ dengan df 29. Dapat disimpulkan bahwa pretest dan posttest kelompok eksperimen signifikan karena dari hasil tabel di dapat $\mathrm{t}_{\mathrm{h}}>\mathrm{t}_{\mathrm{t}}$ dan $\mathrm{P}<0,05$ sesuai dengan Syarat dan bersifat signifikansi apabila $\mathrm{t}_{\text {hitung }}$ lebih besar dari $\mathrm{t}_{\text {tabel }}$ dan $\mathrm{P}$ lebih kecil dari $0,05(5 \%)$.

Berdasarkan hasil skor pretest dan posttest dapat disimpulkan bahwa kelompok kontrol yang melaksanakan pembelajaran dengan menggunakan media konvensional menunjukkan tidak ada perbedaan yang signifikan. Berbeda dengan hasil skor pretest dan posttest kelompok eksperimen yang melaksanakan pembelajaran yang menggunakan media vlog menunjukkan adanya perbedaan yang signifikan. Data tersebut menunjukkan bahwa terdapat perbedaan yang signifikan antara kemampuan awal dan akhir pembelajaran menulis teks berita pada kelompok eksperimen. Dengan kata lain, terdapat peningkatan hasil skor yang signifikan setelah diberi perlakuan dengan menggunakan media vlog. Berdasarkan hal itu dapat disimpulkan bahwa penggunaan media vlog dalam pembelajaran menulis teks berita lebih efektif dari pada pembelajaran menyimak puisi dengan menggunakan media konvensional.

\section{KESIMPULAN}

1. Terdapat perbedaan pembelajaran menulis teks berita siswa kelas VII SMP Negeri 2 Gamping antara kelompok yang mendapat pembelajaran dengan menggunakan medi vlog. Perbedaan pembelajaran menulis teks berita tersebut ditunjukkan dengan hasil uji-t posttest kelompok kontrol dan posttest kelompok eksperimen, yaitu Hasil perolehan nilai thitung sebesar 1.382 dengan df sebesar 58. Kemudian skor $t_{\text {hitung }}$ tersebut dikonsultasikan dengan nilai $t_{\text {tabel }}$ pada taraf signifikan 0,05 dan df 58 . Skor $\mathrm{t}_{\text {tabel }}$ pada taraf signifikansi $5 \%$ dan df 58 adalah sebesar 6.661. hal ini menunjukkan bahwa skor $t_{\text {hitung }}$ lebih kecil dari $t_{\text {tabel }}(1.382<$ 6.661) dan sig (P) lebih kecil dari $0,05(.000<$ $0,05)$ maka dinyatakan posttest kelompok eksperimen dan kelompok kontrol signifikan karena memenuhi syarat taraf signifikan dimana $t_{\text {hitung }}$ kurang dari $t_{\text {tabel }}$ sedangkan $P$ kurang dari taraf signifikan 5\%. Dengan demikian hasil uji-t tersebut menunjukkan terdapat perbedaan pembelajaran menulis teks berita yang signifikan antara kelompok eksperimen yang mendapat pembelajaran dengan menggunkan media vlog dan kelompok kontrol yang menggunakan media konvensional.

2. Pembelajaran menulis teks berita siswa kelas VII SMP Negeri 2 Gamping dengan menggunkan media vlog lebih efektif dibandingkan pembelajaran menulis teks berita dengan menggunakan media konvensional. Hal tersebut ditunjukkan dengan hasil uji-t data pretest dan posttest pembelajaran menyimak puisi kelompok eksperimen diperoleh $t_{\text {hitung }}$ sebesar $21.200, \mathrm{t}_{\text {tabel }}$ sebesar 6.878 (21.200>6.878), dan $P$ sebesar 0,000 pada taraf signifikan $0,05(\mathrm{P}>0,05)$ dengan $\mathrm{df}$ 29. Dapat disimpulkan bahwa pretest dan posttest kelompok eksperimen signifikan karena dari hasil tabel di dapat $t_{\text {hitung }}>t_{\text {tabel }}$ dan $\mathrm{P}<0,05$ sesuai dengan Syarat dan bersifat signifikansi apabila $t_{\text {hitung }}$ lebih besar dari $t_{\text {tabel }}$ dan P lebih kecil dari 0,05 (5\%). Berdasarkan hasil skor pretest dan posttest dapat disimpulkan bahwa kelompok eksperimen yang melaksanakan pembelajaran yang menggunakan media vlog menunjukkan efektif digunakan dalam pembelajaran menyimak puisi.

\section{DAFTAR PUSTAKA}

Arikunta Suharsimi. 2014. Prosedur Penelitian. Jakarta: Rineka Cipta

Azhar Arsyad. 2017. Media Pembelajaran. Jakarta:Rajagrafindo Persada.

Darmawan, Deni. 2013. Metode Penelitian Kuantitatif. Bandung: PT Remaja Rosdakarya

Jubilee. 2018. Kitab Youtuber. Jakarta:Elex Media.

Kustandi,C, dan Sutjipto,B. 2011. Media Pembelajaran Manual dan Digital. Bogor:Galia Indonesia.

Sri Anitah. 2010. Media Pembelajaran Surakarta:Yuma Pustaka.

Tarigan, Henry Guntur.2008. Menulis Sebagai Suatu Keterampilan Berbahasa. Bandung:Angkasa Bandung

Wina Sanjaya. 2008. Perencanaa dan Desain Sistem Pembelajaran. Jakarta:Prenadamedia.

Yunus, Syarifudin. 2015. Kompetensi Menulis Kreatif. 2015:Ghalia Indonesia. 